\section{Pacific Northwest}

National Laboratory

Operated by Battelle for the

U.S. Department of Energy

\title{
Calibration Systems Final Report
}

\author{
T. L. Myers \\ B. T. Broocks \\ M. C. Phillips
}

February 2006

Prepared for the U.S. Department of Energy

under Contract DE-AC05-76RL01830

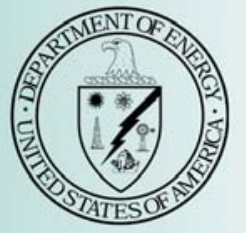




\title{
DISCLAIMER
}

This report was prepared as an account of work sponsored by an agency of the United States Government. Neither the United States Government nor any agency thereof, nor Battelle Memorial Institute, nor any of their employees, makes any warranty, express or implied, or assumes any legal liability or responsibility for the accuracy, completeness, or usefulness of any information, apparatus, product, or process disclosed, or represents that its use would not infringe privately owned rights. Reference herein to any specific commercial product, process, or service by trade name, trademark, manufacturer, or otherwise does not necessarily constitute or imply its endorsement, recommendation, or favoring by the United States Government or any agency thereof, or Battelle Memorial Institute. The views and opinions of authors expressed herein do not necessarily state or reflect those of the United States Government or any agency thereof.

\author{
PACIFIC NORTHWEST NATIONAL LABORATORY \\ operated by \\ BATTELLE \\ for the \\ UNITED STATES DEPARTMENT OF ENERGY \\ under Contract DE-AC05-76RL01830
}

Printed in the United States of America
Available to DOE and DOE contractors from the Office of Scientific and Technical Information,
P.O. Box 62, Oak Ridge, TN 37831-0062;
ph: (865) 576-8401
fax: $(865)$ 576-5728
email: reports@adonis.osti.gov

\begin{abstract}
Available to the public from the National Technical Information Service, U.S. Department of Commerce, 5285 Port Royal Rd., Springfield, VA 22161 ph: (800) 553-6847 fax: $(703) 605-6900$ email: orders@ntis.fedworld.gov online ordering: http://www.ntis.gov/ordering.htm
\end{abstract}

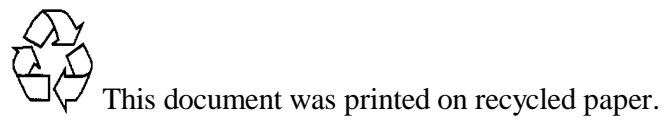




\title{
Calibration Systems Final Report
}

\author{
T. L. Myers \\ B. T. Broocks \\ M. C. Phillips
}

February 2006

Prepared for

the U.S. Department of Energy under Contract DE-AC05-76RL01830

Pacific Northwest National Laboratory Richland, Washington 99352 



\section{Summary}

The Calibration Systems project at Pacific Northwest National Laboratory (PNNL) is aimed towards developing and demonstrating compact Quantum Cascade (QC) laser-based calibration systems for infrared imaging systems. These on-board systems will improve the calibration technology for passive sensors, which enable stand-off detection for the proliferation or use of weapons of mass destruction, by replacing on-board blackbodies with QC laser-based systems. This alternative technology can minimize the impact on instrument size and weight while improving the quality of instruments for a variety of missions. The potential of replacing flight blackbodies is made feasible by the high output, stability, and repeatability of the QC laser spectral radiance.

In FY05, PNNL explored a variety of operating schemes to obtain a range of radiance levels that can be used for a linearity check of the detector response. Performance goals are five radiance levels in less than two minutes with $1 \%$ stability. The current of the QC laser is ramped to change the output power on a rapid timescale, and the temperature of the dewar is actively controlled. Currently, cryogenic lasers are being tested since thermoelectrically-cooled single-mode QCLs that operate cw are still in their infancy. PNNL has identified an approach that provides six radiance levels with $1 \%$ stability, but tests are still ongoing to confirm the long-term reproducibility of the output power with this scheme. For this report, up to 18,000 cycles have been completed with no observable degradation in output power. The uncertainty is $2 \%$ due to a cyclic variation that is observed.

In FY05, PNNL has also begun investigating the most promising design features for QC lasers for wavelength calibration. QC lasers can be designed to emit light throughout the 3 to $14 \mu \mathrm{m}$ region, and their small size allows them to be multiplexed to span different spectral regions of interest. However, the frequency range of a conventional QC laser with just current tuning is limited (only 1-2 wavenumbers) so that at least 4-5 QC lasers would be required to access discrete wavelengths throughout the relevant spectral region $(7.5-13.5 \mu \mathrm{m})$. Thus, PNNL is partnering with Princeton University to optimize the QCL design to provide access to multiple wavelengths with a monolithic QC device in order to minimize the number of lasers required to span the $7.5-13.5 \mu \mathrm{m}$ spectral region. 



\section{Contents}

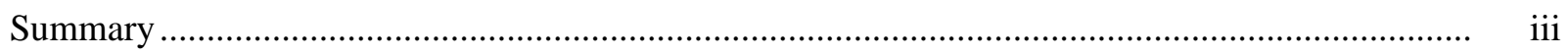

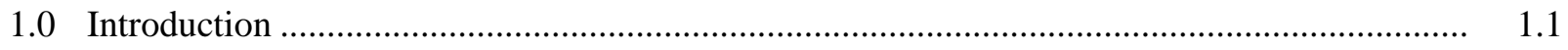

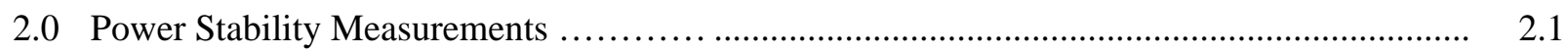

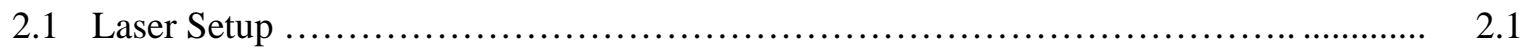

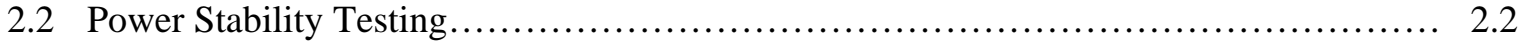

2.2.1 Stability with lock-in detection and MCT detector....................... 2.2

2.2.2 Stability with a thermopile detector........................................ 2.7

2.3 Scheme for Optimal Power Stability and Range of Radiometric Levels ................ 2.9

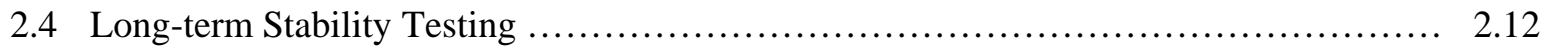

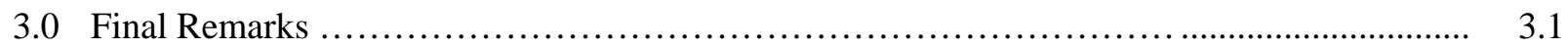




\section{Figures}

2.1 Measured signal from a laser at a set current and temperature over two hours using lock-in detection along with a MCT detector

2.2 Effect of ambient air temperature on detected signal.

2.3 Measured signal from a laser at a set current and temperature over three days using lock-in detection with a MCT detector

2.4 Measured signal for the laser below threshold over three days using lock-in detection with a MCT

detector

2.5 MCT response over different current levels

2.6 Power over different current levels measured with a thermopile detector

2.7 Measured signal from a modulated laser using an integrating sphere and MCT detector

2.8 Measured laser stability using a thermopile detector at a set current and temperature

2.9 Power meter fluctuations with no laser light over a 1 hour time period

2.10 Output power stability over three consecutive days using a power meter.

2.11 Multi-level scheme that provides seven radiance levels

2.12 Multi-level scheme that provides six radiance levels

2.13 Measured power stability for the fourth radiance level over 88 loops

2.14 Measured power stability over 12 days for the fourth radiance level

2.15 Measured power stability for the fourth radiance level over 256 loops

2.16 Measured output power for the fourth radiance level over 17,889 cycles

2.17 Measured output power for the first radiance level over 17,889 cycles

2.18 Effect of dewar cap position on output power. 


\section{Tables}

2.1 Power stability for the seven radiance levels measured 10 times throughout the day

2.2 Current and time period for each step in the calibration cycle

2.3 Data demonstrating power stability for all six radiance levels over 88 loops

2.4 Data demonstrating power stability for all six radiance levels over 12 days.

2.5 Data demonstrating power stability for all six radiance levels over 256 loops

2.6 Data demonstrating power stability for all six radiance levels over 17,889 cycles .... 



\subsection{Introduction}

The sensitivity of passive hyperspectral imaging spectrometers in the long-wavelength infrared (LWIR) spectral region is limited by the ability to achieve an accurate, pixel-to-pixel calibration of the detector elements composing the Focal Plane Array (FPA). Focal-plane arrays can suffer from some degree of non-uniform gain and offsets so that each pixel in the array does not produce an identical electrical signal when exposed to an equal number of photons. An extensive calibration on the ground is usually performed to account for these nonuniformities. This pre-launch calibration, however, doesn't simulate all of the operational conditions of the sensor such as a moving platform or the pressure and temperature fluctuations. These fluctuations in the surroundings can cause the gain and offset of the detector to drift slowly and randomly in time. Thus, an on-board calibration system is required to monitor the system performance over time and account for changes in the detector response.

This task can be especially challenging for flight and satellite-based instruments where size, weight, and power consumption must be minimized. Many instruments incorporate two internal blackbodies, which are used to provide a linear check for the pixel response since multi-level radiance schemes suffer from being time-consuming and hardware intensive. An alternative option is to replace blackbodies with quantum cascade (QC) lasers, which can potentially reduce the size, weight, and power requirements compared to conventional blackbodies. For reference, most flight blackbodies have a diameter on the scale of inches and weigh several pounds. In contrast, a typical QC laser measures less than $1 \mathrm{~mm}$ across and $3 \mathrm{~mm}$ in length and weighs a fraction of a gram. Furthermore, the power consumption for just one blackbody is typically around 6 Watts, and most systems continuously maintain the power to the blackbodies for stability. By using QC lasers, the power consumption can be dramatically reduced by using a scheme that turns on the power to the calibration system only during the actual calibration event. The output power can be adjusted rapidly to span the dynamic range of the detector and fit any higher order structure on a faster timescale. Additionally, QC lasers can be tailored to emit light throughout the infrared region $(3.5-17 \mu \mathrm{m})$ so that they can overlap the spectral region of interest. The high output power, stability, and repeatability of the QC laser spectral radiance enable QC lasers to be a viable alternative for on-board blackbodies.

Compact quantum cascade (QC) laser-based calibration systems for infrared imaging instruments will improve the calibration technology for passive sensors, which enable stand-off detection for the proliferation or use of weapons of mass destruction, by replacing on-board blackbodies with QC laserbased systems. QC lasers offer significant advantages over conventional blackbodies, including higher spectral radiant power, faster time response to support measurement of the nonlinearities in the detector response, and reduced size, weight, and power consumption. Not only could these systems potentially eliminate the requirement for on-board blackbodies, but depending on where the signal is inserted they may also provide a better linearity check for all of the pixels by increasing the number of radiance levels used in the radiometric calibration. 



\subsection{Power Stability Measurements}

These tests examine the short and long-term power stability of a conventional single-mode QC laser when the laser is tuned over different current levels to change the output power. These multiple radiance levels can be used to provide an enhanced linearity check compared to a typical two-point blackbody calibration scheme. Performance goals include $1 \%$ power stability over a dynamic range of 25 in a timescale of less than two minutes with a calibration cycle occurring about every 30 minutes to reflect a typical scenario for a satellite platform. PNNL also performs accelerated testing to determine a typical lifetime for the QC device using this multi-radiance level scheme.

\subsection{Laser Set-up}

PNNL mounted a laser chip assembly (M307Gc-2) from Maxion in a standard dewar from Laser Components (L5736). Two single-mode QC lasers with a wavelength around $8.4 \mu \mathrm{m}$ are wire-bonded on this laser chip assembly. The L-bracket in the dewar is removed, and a new mounting plate is attached so that the laser chip assembly can be directly bolted to this mounting plate. To obtain stable output power and frequency, reliable temperature control is crucial. Thus, a heater is epoxied to the mounting plate and a silicon diode temperature sensor from Lakeshore (DT670) is attached to the mounting plate directly underneath the laser. The temperature sensor is not mounted directly on the laser chip assembly due to space limitations. A four-wire measurement scheme in which the current leads and voltage leads are run separately up to the temperature sensor is used to eliminate the effect of lead resistance on the measurement. A Lakeshore $332 \mathrm{~S}$ temperature controller is used for closed loop temperature control.

The initial testing used a Keithley 24203 A source meter to supply the current to the QC laser. PNNL wrote a software program in LabView to control the laser and measure the signal. At one point, the laser died when the program had been stopped and then restarted, which may have caused a voltage spike that damaged the laser. Excessive voltage due to power-supply transients can be hazardous to semiconductor diode lasers. Many power supplies produce voltage spikes during turn-on or turn-off and these voltage spikes can be large enough to cause damage to the laser. Therefore, PNNL began using its custom current controllers that have been developed under previous DARPA and NA-22 funding to avoid detrimental voltage spikes from unanticipated situations such as power failures or software glitches. These current controllers are precisely controlled, are low noise, are limited to 1 A of maximum current, and don't suffer from power supply transients. PNNL then began testing the second laser off the same laser chip assembly for the final configuration since the first laser had been damaged. No damage to this laser has occurred since switching to the custom current controllers. 


\subsection{Power Stability Testing}

The first step required choosing a technique to measure the short and long-term power stability of the QC laser. PNNL investigated two different options:

1) Using a $\mathrm{HgCdTe}(\mathrm{MCT})$ detector along with an optical chopper for lock-in detection or

2) Using a thermopile detector to measure the output power.

\subsubsection{Stability with lock-in detection and MCT detector}

PNNL tested the power stability using a Fermionics photovoltaic MCT detector that has a 1 $\mathrm{mm}^{2}$ active area and a wavelength cut-off at 11 microns. A gold-coated optical chopper in front of the laser dewar is used to enable lock-in detection with a Stanford Research Systems SR830 lock-in amplifier. The laser beam is not collimated so that the area of the laser beam is larger than the area of the detector aperture. The detector is positioned directly in front of the dewar and no optics are used for focusing light onto the detector. Figure 2.1 shows a typical data plot in which the laser is controlled at a constant current and the dewar temperature is actively stabilized at $90 \mathrm{~K}$. The percent uncertainty, which is defined as two standard deviations $(2 \sigma)$ over the mean, is $1.2 \%$ over two hours. The measured signal using this scheme exhibits high amplitude $(\sim 0.8 \%)$ low frequency $\left(\sim 1 / 20 \mathrm{~min}^{-1}\right)$ oscillations, which are most likely due to fluctuations from the heating, ventilation, and air conditioning (HVAC) system in the room.

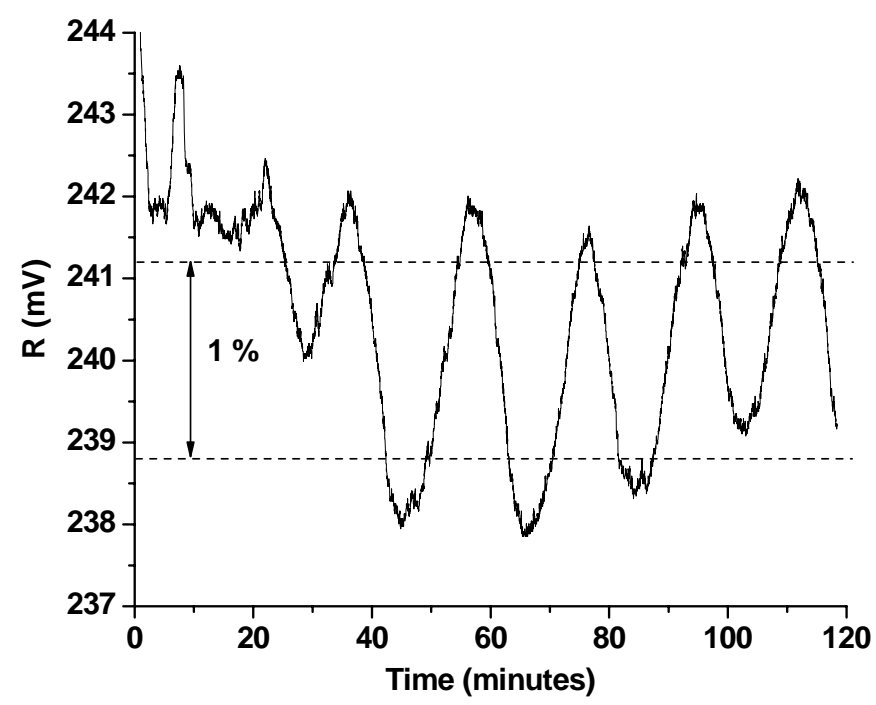

Figure 2.1. Measured signal from a laser at a set current and temperature over two hours using lock-in detection along with a MCT detector. The dashed lines correspond to a $1 \%$ variation. 
To determine if these oscillations resulted from temperature fluctuations in the laboratory, PNNL also measured the signal from a black anodized aluminum block located $20 \mathrm{~cm}$ away from the MCT detector. The chopper is placed right in front of the MCT detector with a chopping frequency of $200 \mathrm{~Hz}$. The MCT signal is amplified using a Stanford Research Systems SR570 current preamplifier, which is connected to the lock-in detector. This signal is shown in the top panel of Figure 2.2. The bottom panel of Figure 2.2 shows the ambient air temperature in the laboratory for comparison. Both panels exhibit oscillations that result from fluctuations in the HVAC. The low frequency oscillations are on a similar timescale to the data presented in Figure 2.1 suggesting that these oscillations do result from ambient air fluctuations in the laboratory.

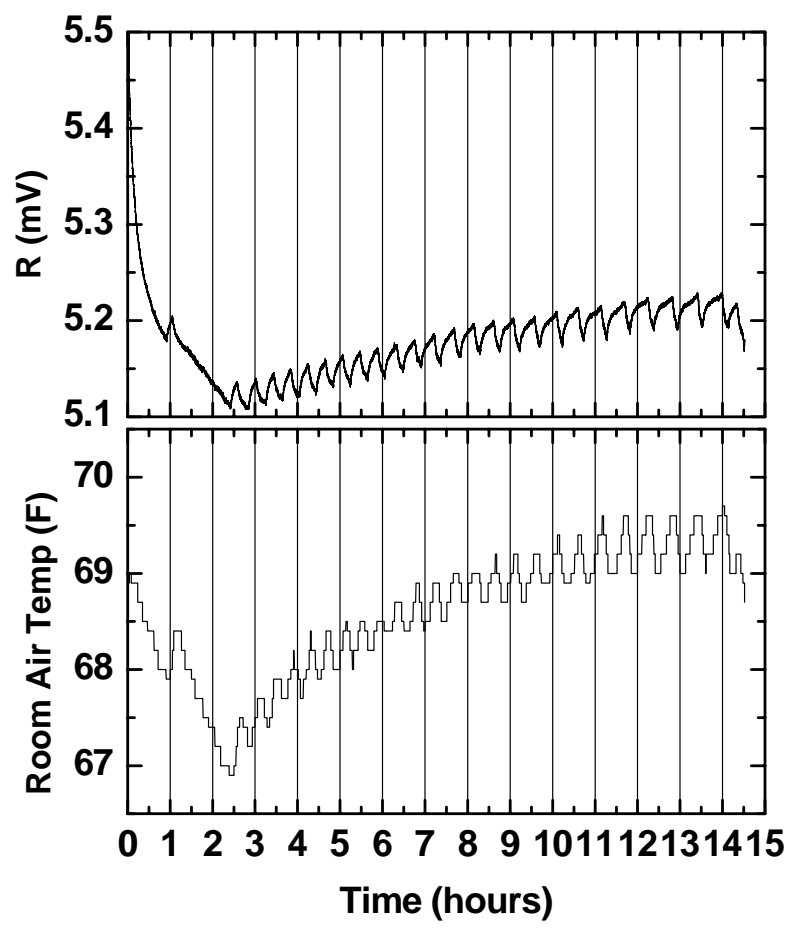

Figure 2.2. Effect of ambient air temperature on detected signal. The top figure shows the lock-in signal for a black anodized aluminum block. The bottom figure shows the measured room temperature.

PNNL also tested the repeatability of this detection scheme using a single MCT detector with lock-in detection. For this test, PNNL actually ramps the current over several radiance levels, but for simplicity, only one current level is presented. Figure 2.3 shows a typical plot of the measured signal over a 3-day time period when the laser current is set to $-332 \mathrm{~mA}$, and the temperature is actively controlled to $87 \mathrm{~K}$. Each data point is 5 minutes apart. For this plot, the uncertainty in the signal is $1.9 \%$ (reported as $2 \sigma$ ). The vertical dashed lines correspond to breaks in the data collection in which PNNL topped off both the laser and MCT dewars with liquid nitrogen and let the system equilibrate for approximately 40 minutes before initiating data collection. The solid lines correspond to the three different days of data collection. The measured uncertainty using this technique is higher than the desired $1 \%$ stability. 


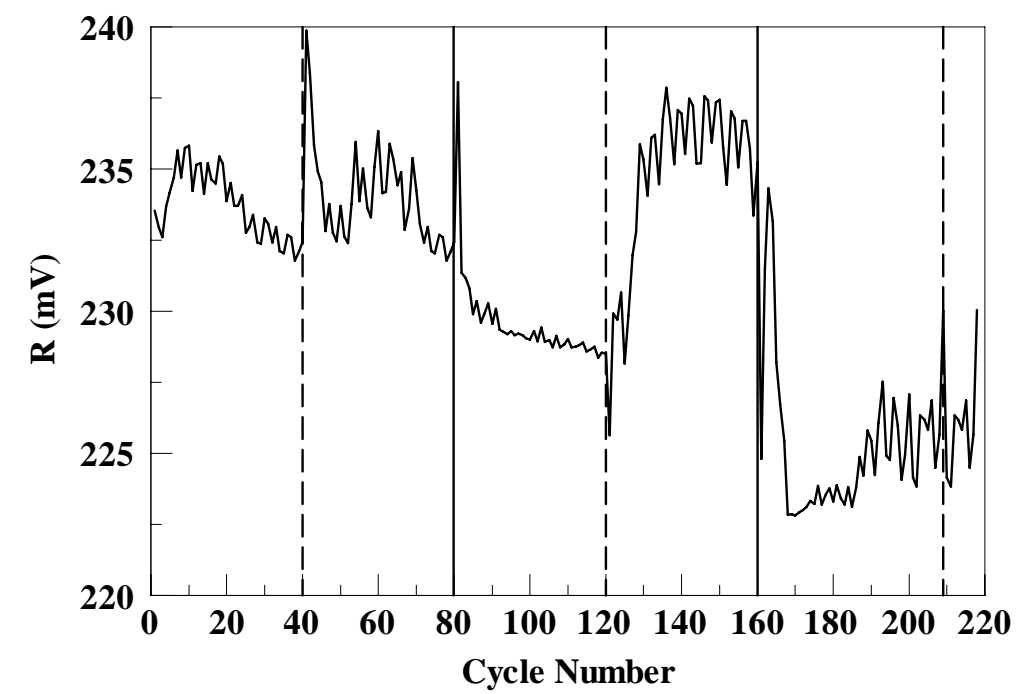

Figure 2.3. Measured signal from a laser at a set current and temperature over three days using lock-in detection with a MCT detector. The dashed lines correspond to temporary breaks in the data collection during the same day, and the solid lines correspond to the three different days of data collection.

Figure 2.4 is similar to Figure 2.3 but demonstrates the measured signal when the laser is below threshold. This data is collected at the start of each scan in Figure 2.3. Although the detector does not observe laser power, it does observe thermal radiation from the heater and laser.

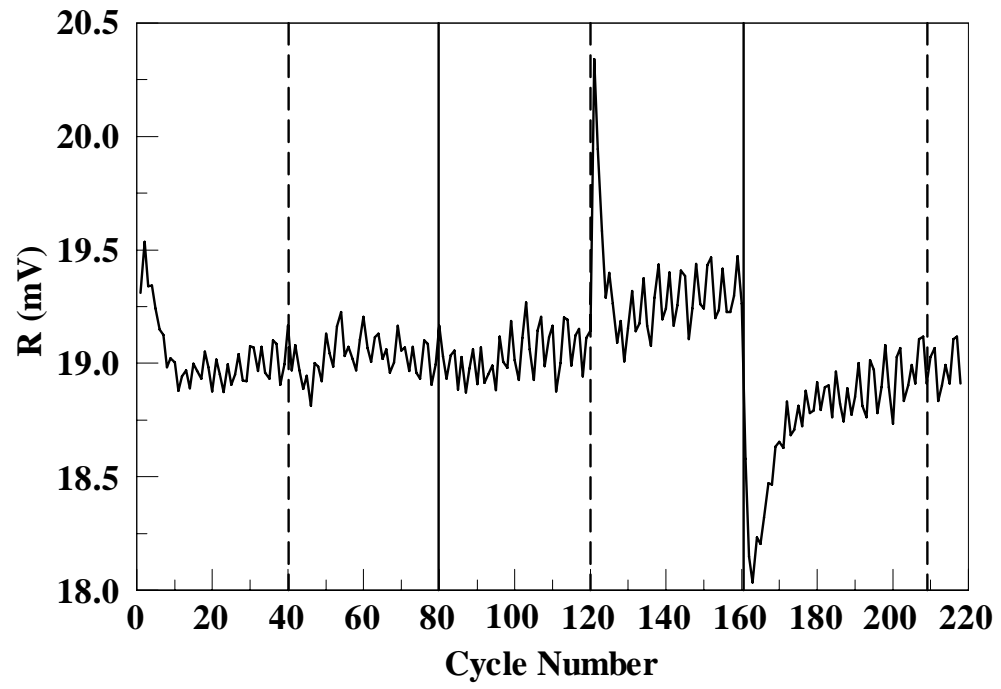

Figure 2.4. Measured signal for the laser below threshold over three days using lock-in detection with a MCT detector. The dashed lines correspond to temporary breaks in the data collection during the same day, and the solid lines correspond to the three different days of data collection. 
Changes in the background signal are typically most significant upon the initial start of the data collection after the dewars have been topped off with liquid nitrogen as indicated by spikes after a solid or dashed line in Figure 2.4. Generally, PNNL allows the system to equilibrate for at least 40 minutes after liquid nitrogen is added. The lock-in amplifier should not be sensitive to changes in the DC offset but is sensitive to changes in the detector responsivity or thermal changes in the field of view of the detector. These spikes are also observed in Figure 2.3 but are of opposite magnitude to the background signal in Figure 2.4. The two plots do not completely track one another, however, and accounting for the signal below threshold does not help with the measurement stability.

An examination of the linearity of the detector over the range used in these experiments shows that the MCT detector is not completely linear over the entire dynamic range tested. Figure 2.5 shows the measured lock-in signal versus laser current. The signal versus laser current begins to deviate from a linear response at the highest current level even though a bias of -100 $\mathrm{mV}$ is applied to the MCT detector.

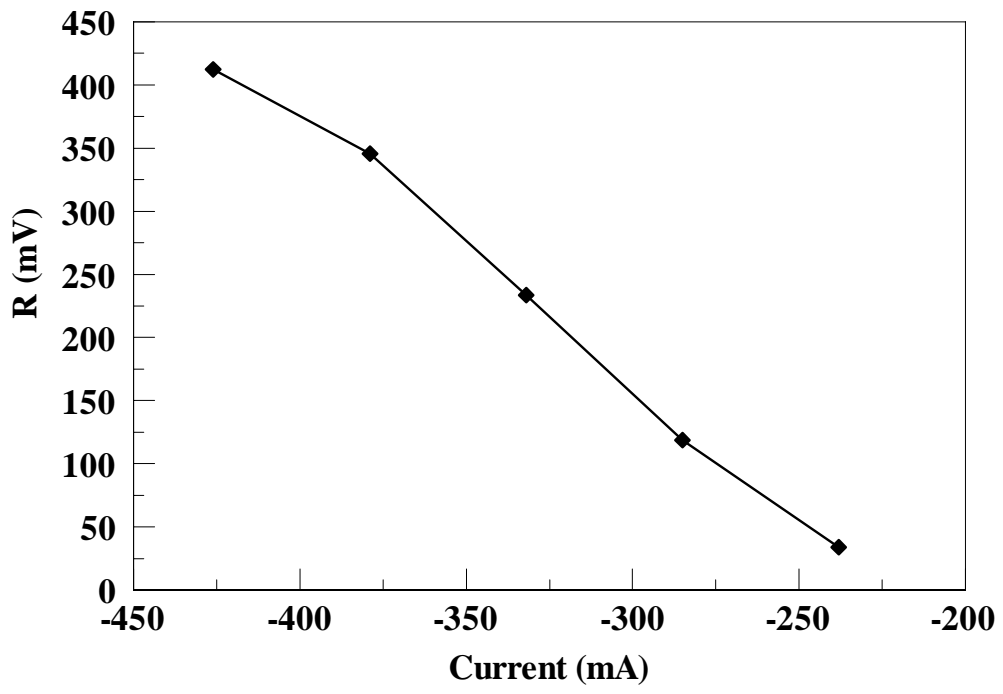

Figure 2.5. MCT response over different current levels.

Figure 2.6 shows a similar examination of the power versus current using a thermopile detector, which should provide a linear response over a large dynamic range. This plot shows the laser power is fairly linear over this range even at the highest current level. Thus, the nonlinearity that is observed at the highest current level is most likely due to the changes in the responsivity of the MCT detector. Thus, PNNL did not pursue MCT detection to look at the QC power stability due to the observed nonlinearity at the highest current level and due to the challenges with the measurement stability and repeatability. 


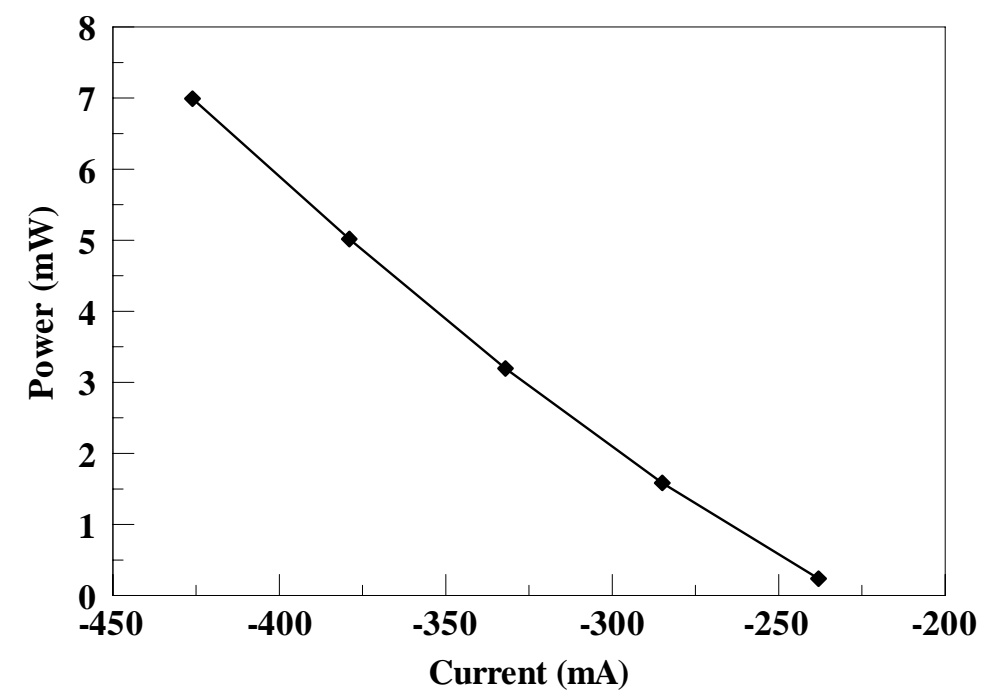

Figure 2.6. Power over different current levels measured with a thermopile detector.

PNNL did explore a couple of alternative detection schemes using a MCT detector to determine if improvements could be achieved. For instance, PNNL also modulated the laser current for lock-in detection in order to omit the optical chopper and avoid the 1/f noise by modulating the laser at high frequencies $(32 \mathrm{kHz})$. The measured signal still showed about $1 \%$ uncertainty over two hours. One method that did provide a more stable measurement is to use an integrating sphere immediately after the dewar and then place the MCT detector at the exit port of the integrating sphere. For this scheme, PNNL used a 2" integrating sphere with a 1" entrance port and a 0.5 " exit port. The laser current was modulated to cycle the power eliminating the requirement for an optical chopper. Figure 2.7 shows the lock-in signal that results when the laser is stabilized to a set current and temperature. The signal levels are lower due to reduced throughput from the integrating sphere. The oscillations are still observed but the amplitude is smaller so that the uncertainty using this technique is only $0.25 \%$ for almost 10 hours of operation. This improvement, however, is not achieved with the integrating sphere if an optical chopper is used instead of modulating the laser current for lock-in detection. Under similar conditions but with an optical chopper, about $1 \%$ uncertainty is achieved over a similar timeframe. The optical chopper operates at lower frequencies $(350 \mathrm{~Hz})$ compared to the laser modulation that is used so that $1 / \mathrm{f}$ noise could be a contributing factor. A more likely explanation, however, is just that the optical chopper provides a pathway for the fluctuating thermal background signals to reach the detector, which limits the uncertainty. Thus, the improved measurement sensitivity requires modulating the laser current (i.e. no optical chopper) and using an integrating sphere to provide a nearly Lambertian source of light at the MCT detector. PNNL did not pursue this technique due to the low signal levels and the requirement for current modulation. 


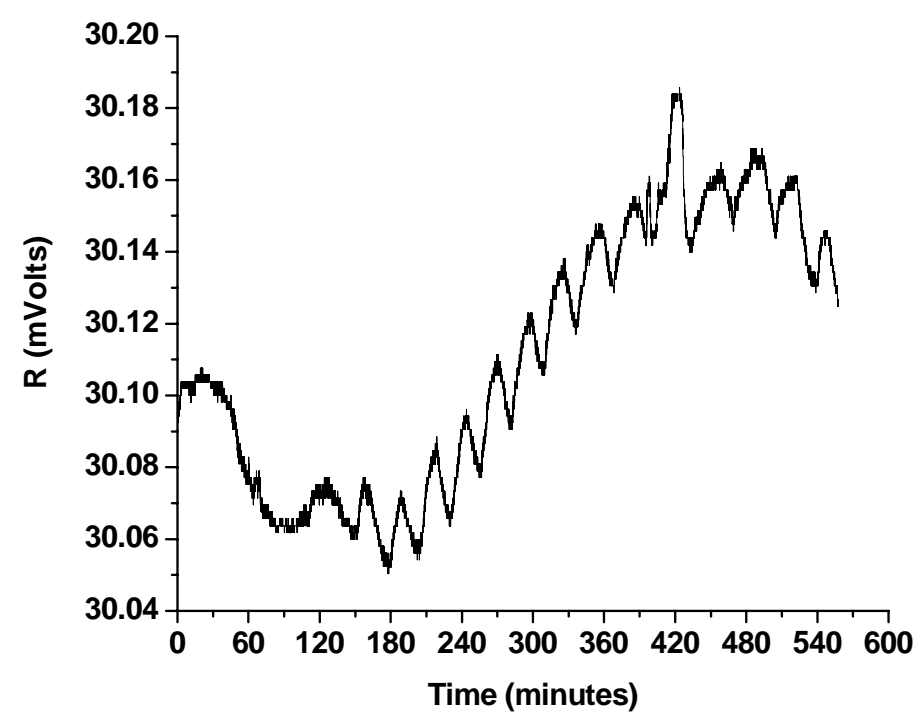

Figure 2.7. Measured signal from a modulated laser using an integrating sphere and MCT detector.

\subsubsection{Stability with a thermopile detector}

PNNL also investigated using a power meter, which is a thermopile detector, to measure the laser power. A thermopile detector produces an electrical voltage from optical radiation incident on its surface that is coated with a black, broadband, absorbing material. The detector has an array of thermocouples that produce a voltage in proportion to the temperature rise. Once the temperature reaches a steady state, the voltage is proportional to the laser power. Thus, thermopiles typically have a slow response and can take several seconds to reach equilibrium.

For these measurements, PNNL uses a Molectron PS10 thermally-stable amplified detector along with a Molectron 3sigma power meter to display the correlating power. The thermal probe has a $10 \mathrm{~mm}$ aperture, which is coated for wavelengths ranging from 0.3 to 11 microns, and is placed in front of the dewar to collect most of the uncollimated light from the front facet of the QC laser. This power meter has a 2 second response time with a minimum resolution of $10 \mu \mathrm{W}$. The thermal drift is quoted as $40 \mu$ Watts over 30 minutes. Due to the high sensitivity along with the broadband coating, the power meter responds to all sources of radiation including thermal background effects and air currents. By using a power meter, however, PNNL can account for most of the thermal drift by zeroing the power meter when no laser power is incident on the probe. PNNL also shields the power meter with closed cell foam to help insulate the power meter from rapid thermal fluctuations in the room, particularly due to personnel moving about the laboratory. Since no focusing optics are used to collect the uncollimated laser beam, the power meter does not collect all of the laser light; thus, only relative power measurements are reported.

With the power meter, PNNL achieved lower uncertainty for the laser power compared to the measurements using lock-in detection with an optical chopper and MCT detector. Figure 2.8 
shows a typical plot for the fluctuations observed with a set current of $-400 \mathrm{~mA}$ and the temperature actively stabilized to $86.5 \mathrm{~K}$. The measured uncertainty is $0.25 \%$ over two hours, which is almost a factor of five better than what is achieved using lock-in detection with a chopper and MCT detector.

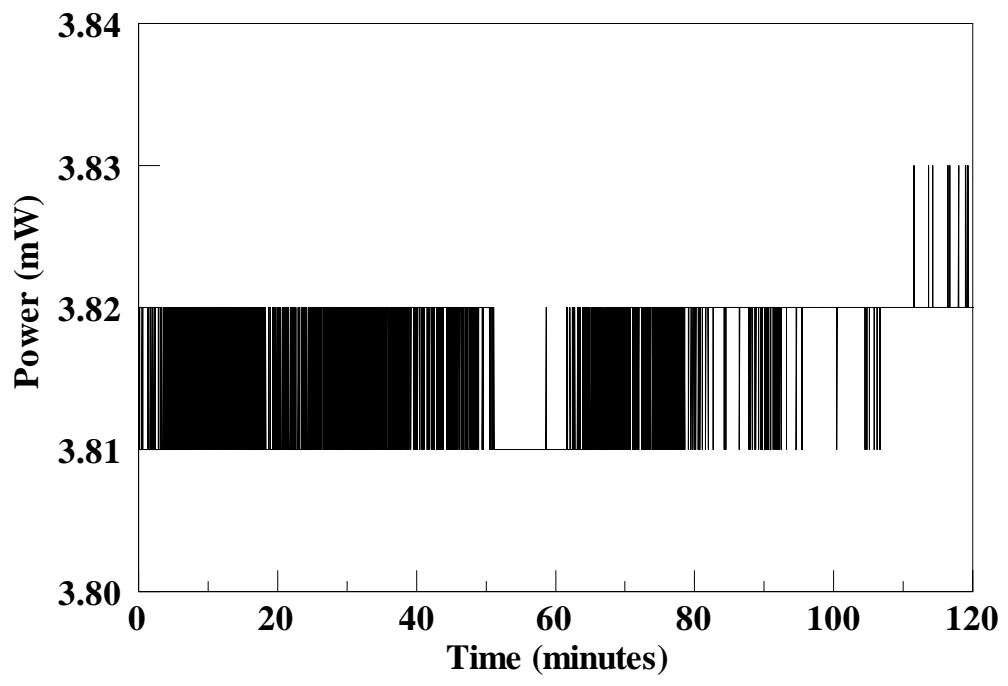

Figure 2.8. Measured laser stability using a thermopile detector at a set current and temperature.

These observed fluctuations are most likely due to thermal drift in the power meter. For example, Figure 2.9 shows typical fluctuations observed in the power meter that is placed in front of the dewar with no current applied to the laser but the temperature of the dewar is actively stabilized. Over 60 minutes, the zero changed by $0.03 \mathrm{~mW}$. Over 15 minutes, the drift is typically $\pm 0.01 \mathrm{~mW}$. PNNL can account for some of this temperature drift by measuring the offset when the laser is below threshold and subtracting this value from measured signal at each radiance level.

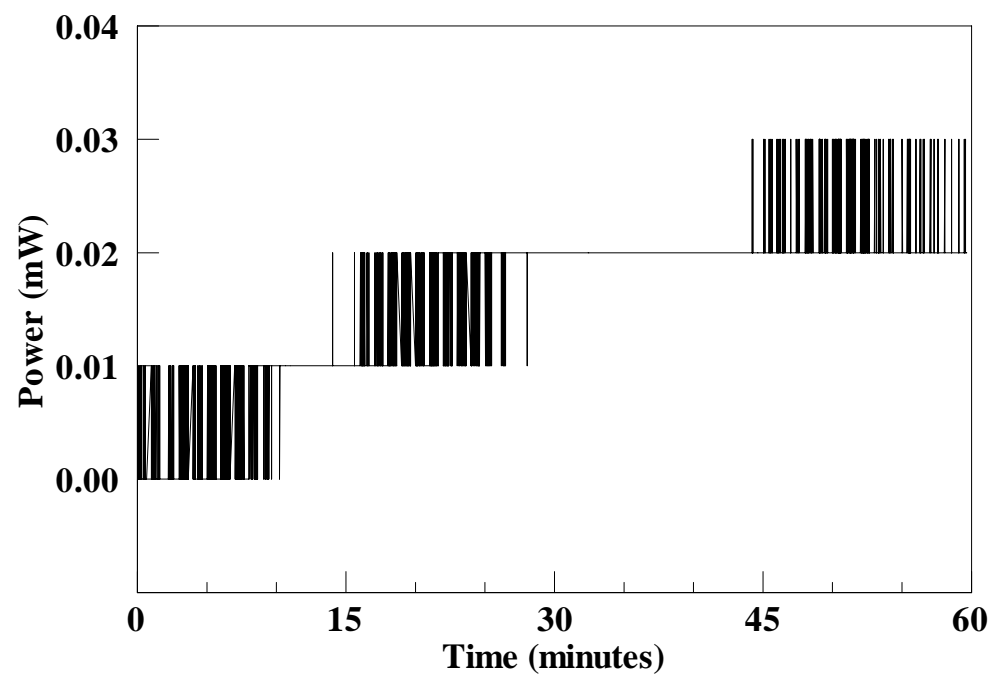

Figure 2.9. Power meter fluctuations with no laser light over a 1 hour time period. 
Better results are also obtained for the repeatability using the power meter compared to lock-in detection with a chopper and MCT detector. Over three days, the signal usually varied less than $\pm 1.0 \%$ except for lowest power levels (i.e. power levels less than $1 \mathrm{~mW}$ ) in which the power meter fluctuations dominate the uncertainty. Figure 2.10 shows typical fluctuations over a 3 -day time period in which signal is collected every 4.5 minutes. The laser current is set to -400 $\mathrm{mA}$ every 4.5 minutes and the temperature is actively controlled to $88 \mathrm{~K}$. The power meter drift is accounted for in each data point by measuring the background signal from the power meter at $200 \mathrm{~mA}$, which is below the laser threshold. This offset is then subtracted from the actual measured signal for each data point. For this plot, the signal uncertainty over the three days is $0.6 \%$. Thus, PNNL made the decision to use a power meter for long-term stability testing.

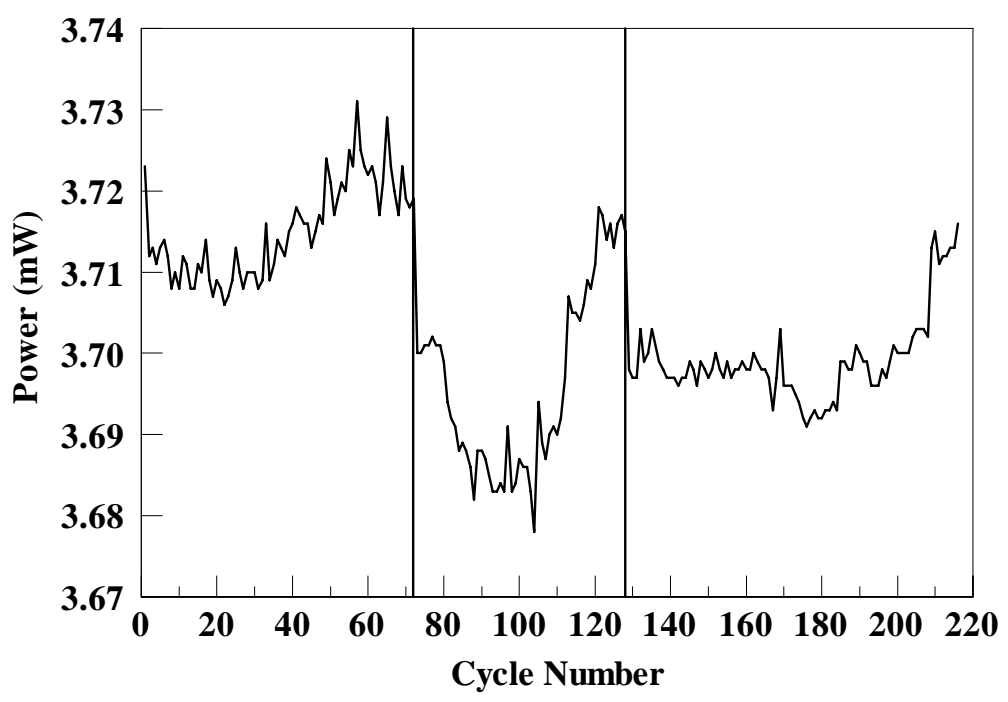

Figure 2.10. Output power stability over three consecutive days using a power meter. The solid lines correspond to the break in data collection.

\subsection{Scheme for Optimal Power Stability and Range of Radiometric Levels}

A scheme to change the power rapidly is needed for looking at the detector response across a range of radiometric levels that would mimic the dynamic range for various systems. PNNL tried different schemes to vary the power on a rapid timescale. Since the current is changed quickly, PNNL obtained the best performance when the temperature is stabilized close to the free-running temperature for the last step so that minimal temperature changes are observed at each step. Temperature stability is important because attempts to correct the output power based on the measured temperature have not been successful using these rapid schemes. PNNL believes this effect is a result of the temperature sensor not providing a true measurement of the active region temperature. For an accurate temperature measurement, the system needs time to settle and equilibrate, especially if thermal lag is present in the system. Thermal lag is due to the finite thermal conductivity of the mounting block and the thermal resistances between the heater, temperature sensor, laser, and mounting block. 
Figure 2.11 shows a scheme that provides seven reproducible radiance levels from a relative power of $0.26 \mathrm{~mW}$ to $4.10 \mathrm{~mW}$. The temperature is actively stabilized at $90 \mathrm{~K}$ and the proportional, integral, differential (PID) parameters are manually set for rapid control. Currently, the proportional $(\mathrm{P})$ term is set to the maximum setting for the highest gain $(\mathrm{P}=1000)$. The integral (I) term is set to provide a time constant of 12.5 seconds $(\mathrm{I}=80)$. The derivative (D) term is set to one fourth the integral time in seconds $(\mathrm{D}=100)$. These parameters are chosen to minimize fluctuations due to the rapid changes in the load as the laser current is ramped. This scheme actually ramps the current over 11 levels, but the first four current levels are below threshold so that they have no affect on the output power. The first two current levels below threshold show the largest fluctuations in temperature since the first step involves a large rise in current. The other two current levels below threshold demonstrate that the system can adapt quickly to the change in laser current to maintain a steady temperature. For the seven steps above threshold, the temperature is stabilized such that the fluctuations are less than $0.01 \mathrm{~K}$ for each step. Each step takes 19 seconds so that the total time for this scheme is almost 3.5 minutes although the time above threshold is only 2 minutes. The time for each step could be reduced further to minimize the timescale for the calibration procedure.
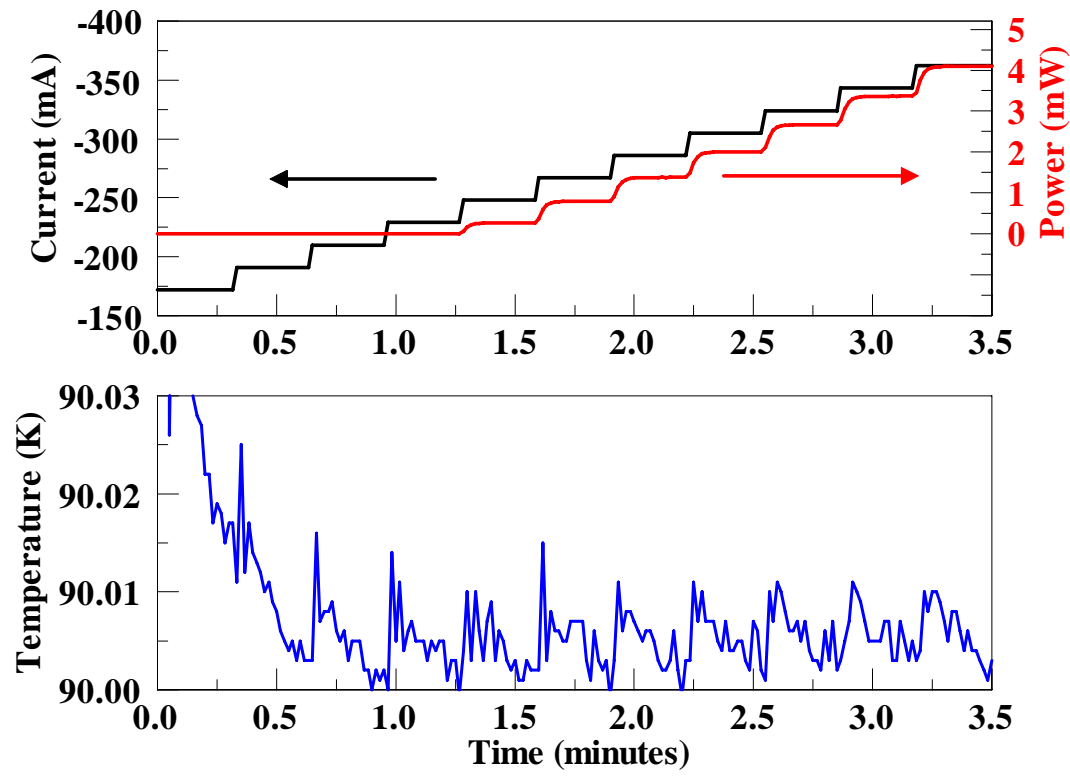

Figure 2.11. Multi-level scheme that provides seven radiance levels. The top graph shows the change in output current (black) along with the relative output power (red). The bottom figure shows the temperature range using this scheme.

PNNL performed this scheme 10 times throughout the day (about every 30 minutes) and observed excellent power stability except at the lowest power levels. Since the power meter stability is limited to $\pm 0.01 \mathrm{~mW}$, more error is observed for power levels below $1 \mathrm{~mW}$. The results for each radiance level are shown in Table 2.1. 
Table 2.1. Power stability for the seven radiance levels measured 10 times throughout the day.

\begin{tabular}{|c|c|c|c|}
\hline $\begin{array}{c}\text { Step } \\
\text { Number }\end{array}$ & $\begin{array}{c}\text { Mean Output Power } \\
(\mathrm{mW})\end{array}$ & Standard Deviation $(2 \sigma)$ & $\begin{array}{c}\text { Normalized Standard } \\
\text { Deviation }(\%)\end{array}$ \\
\hline 1 & 0.26 & .017 & 6.66 \\
\hline 2 & 0.78 & .017 & 2.16 \\
\hline 3 & 1.36 & .017 & 1.24 \\
\hline 4 & 1.99 & .016 & 0.79 \\
\hline 5 & 2.66 & .013 & 0.50 \\
\hline 6 & 3.36 & .015 & 0.44 \\
\hline 7 & 4.10 & .016 & 0.38 \\
\hline
\end{tabular}

To eliminate the effect of thermal drift, the output powers are corrected for the offset on the power meter when no laser power is present. The mean background signal below threshold is subtracted from the data collected.

PNNL modified the scheme to provide six radiance levels ranging from a relative power of about $0.27 \mathrm{~mW}$ to $6.26 \mathrm{~mW}$ for a dynamic range of 23 . Figure 2.12 shows the parameters for the modified scheme. The temperature is actively stabilized to $88 \mathrm{~K}$. The total time of the scheme is 3 minutes with 2 minutes above threshold. Each step lasts for 20 seconds, but it only takes the laser power about 9 seconds to equilibrate so that the step time could be decreased (to a minimum of 10 seconds).
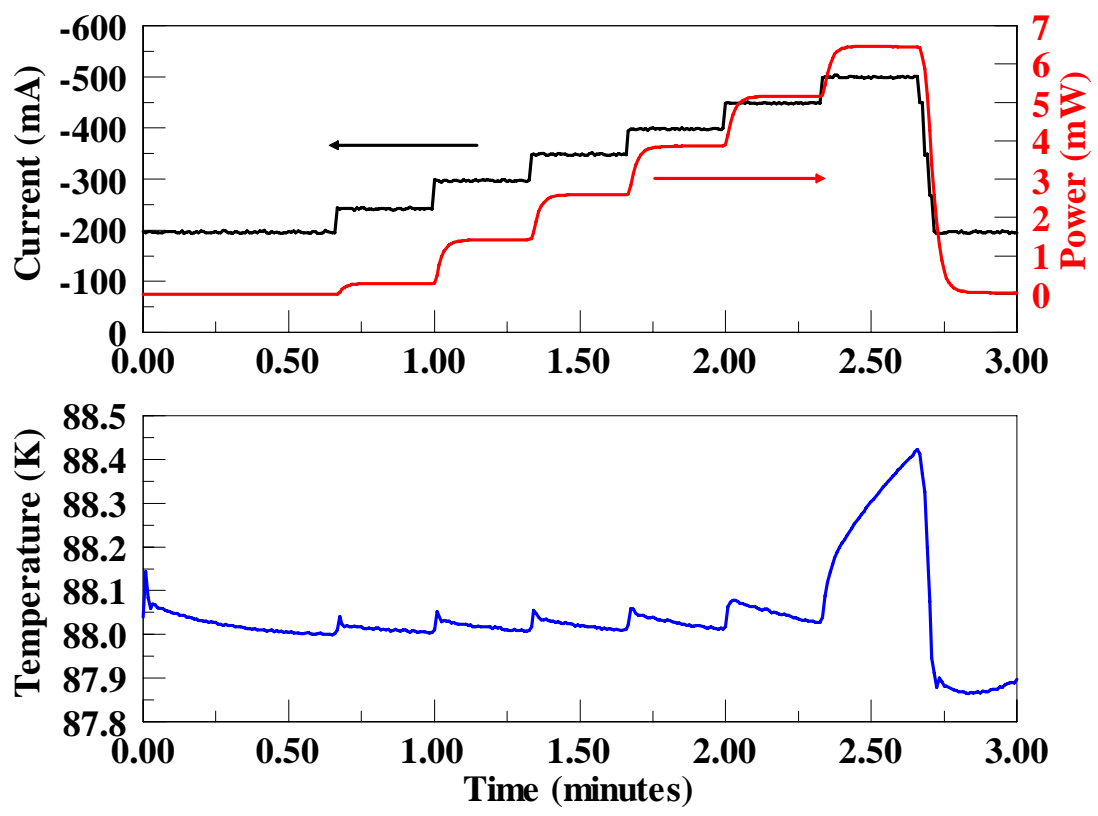

Figure 2.12. Multi-level scheme that provides six radiance levels. The top figure shows the change in current over seven steps in black with the corresponding relative output power in red. The bottom figure shows the temperature change using this scheme. 
The setpoint temperature is below the free-running temperature at the last current level so that the temperature stability is not optimal for the last step. The effect on power with temperature is approximately $-0.1 \mathrm{~mW} / \mathrm{K}$. Since the temperature changes from $88.25 \mathrm{~K}$ to $88.4 \mathrm{~K}$ over the last step, the power should only change by $-0.01 \mathrm{~mW}$, which is within the error of the power meter. Although lower temperature fluctuations for the last step $(\mathrm{T}<.01 \mathrm{~K})$ can be obtained if the system is stabilized at a higher temperature, this scheme provides the required $1 \%$ output power stability. This scheme is used for the long-term stability testing presented in the next section.

\subsection{Long-term Stability Testing}

PNNL incorporated a Lab View program to automate the calibration scheme and data collection. This step allowed PNNL to increase the number of loops collected per day. The laser dewar must still be manually filled with liquid nitrogen so that completely continuous operation is not feasible and the dewar is still thermally cycled about every 12 days. The hold-time of the dewar with the laser in operation is about ten hours. In FY06, PNNL would like to install an auxiliary reservoir to increase the hold time of the dewar.

The Lab View program currently uses one of the auxiliary digital-to-analog (D/A) outputs on a SR830 lock-in amplifier to control the current supply. This programmable output is a 16-bit $\mathrm{D} / \mathrm{A}$ control that can provide voltages from $-10.5 \mathrm{~V}$ to $10.5 \mathrm{~V}$ with $1 \mathrm{mV}$ resolution via a computer interface. The heater for the temperature controller is turned on manually and maintained for closed loop control at the operating temperature of $88 \mathrm{~K}$. The software records data from the power meter and the temperature controller. For the data presented here, the software records the raw data into a file every 0.5 seconds. The software also averages data from each step, after a delay of seven seconds to allow the system to equilibrate, and records this data in a separate file. The software can be modified to change the current and time for each step during a calibration cycle. Table 2.2 shows the operating current and time period for each step in the calibration cycle used for the data in this report. As shown in this table, PNNL incorporated a sequence to decrease the current after the final radiometric step to provide less of a temperature and voltage shock to the system. PNNL also appended the software to collect data from a Vantage PRO weather station in the room to observe any dependence on room temperature, pressure, and humidity. 
Table 2.2. Current and time period for each step in the calibration cycle.

\begin{tabular}{|c|c|}
\hline Current $(\mathrm{mA})$ & Time $(\mathrm{sec})$ \\
\hline-200 & 40 \\
\hline-245 & 20 \\
\hline-300 & 20 \\
\hline-350 & 20 \\
\hline-400 & 20 \\
\hline-450 & 20 \\
\hline-500 & 20 \\
\hline-450 & 1 \\
\hline-350 & 1 \\
\hline-270 & 1 \\
\hline-200 & 20 \\
\hline-50 & 1 \\
\hline
\end{tabular}

The signal measured at $-200 \mathrm{~mA}$ is below threshold and is used to monitor the offset on the power meter that changes with thermal drift. The software averages this signal, which is then subtracted from the raw signal collected at each radiance level. The background signal is also measured at the end of the calibration cycle at the same current of $-200 \mathrm{~mA}$. This final background value, which results from averaging the data for 13 seconds, has an offset of +0.035 $\mathrm{mW}$ compared to the initial background value. This offset results from the bulk heating of the thermal probe during the calibration cycle. Based on the drop in the signal during the background check, PNNL can estimate the equilibration time is approximately $0.0025 \mathrm{~mW} / \mathrm{s}$. Thus, the probe should have fully reached thermal equilibrium after another 14 seconds. The probe has fully reached thermal equilibrium by the time the cycle starts over, which occurs 86 seconds after the last step in the cycle given in Table 2.2. For all of the data presented in this report, PNNL used the offset from the initial background check to correct for the thermal drift.

The power stability over one day is quite good and is currently limited by the power meter stability of $\pm 0.01 \mathrm{~mW}$. For this data, the calibration scheme is initiated every 4.5 minutes for a total of 88 loops. Table 2.3 shows the relative mean power for each radiance level along with the standard deviation (reported as $2 \sigma$ ) and the percent uncertainty. The standard deviation is most likely due to the power meter uncertainty. The uncertainty is under $1 \%$ for most of the steps (except the lowest levels). 
Table 2.3. Data demonstrating power stability for all six radiance levels over 88 loops.

\begin{tabular}{|c|c|c|c|}
\hline $\begin{array}{c}\text { Radiance } \\
\text { Level }\end{array}$ & Mean Power $(\mathrm{mW})$ & $\begin{array}{c}2 \sigma \text { Standard Deviation } \\
(\mathrm{mW})\end{array}$ & $\begin{array}{c}\text { Normalized 2 } \sigma \\
\text { Standard Deviation (\%) }\end{array}$ \\
\hline 1 & 0.276 & .006 & 2.35 \\
\hline 2 & 1.374 & .006 & 0.56 \\
\hline 3 & 2.500 & .008 & 0.36 \\
\hline 4 & 3.699 & .010 & 0.28 \\
\hline 5 & 4.983 & .018 & 0.36 \\
\hline 6 & 6.260 & .022 & 0.38 \\
\hline
\end{tabular}

Figure 2.13 shows the data points for step 4 over the 88 loops illustrating that $1 \%$ power stability is achieved.

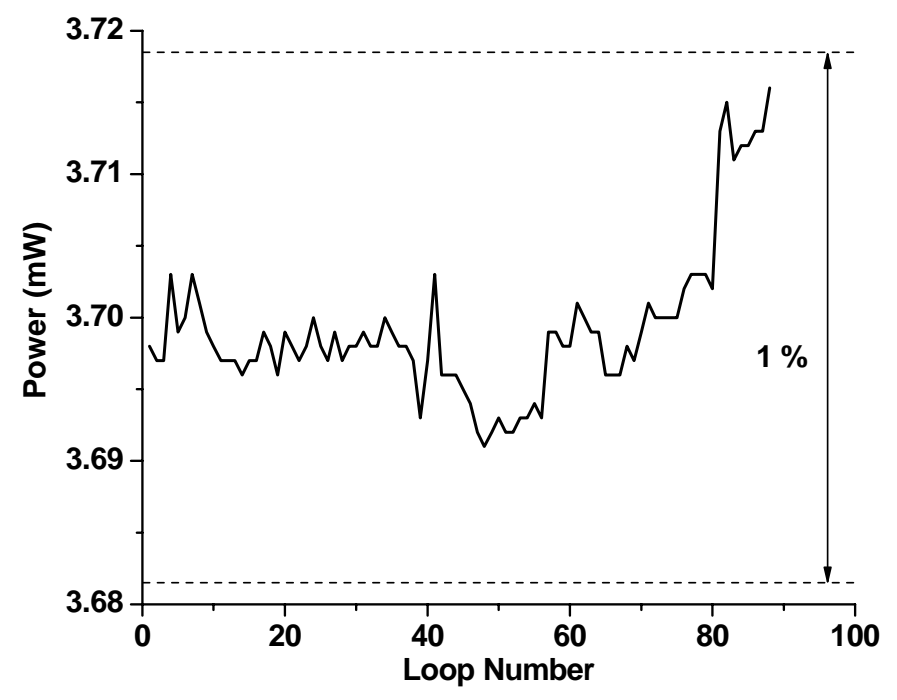

Figure 2.13. Measured power stability for the fourth radiance level over 88 loops.

Over 12 days, in which the dewar is thermally cycled two times, fairly good stability is observed except at the lowest power levels, which are limited by the power meter fluctuations. Table 2.4 shows the relative mean power for each radiance level along with the standard deviation (reported as $2 \sigma$ ) and the percent uncertainty. The uncertainty is under $1.5 \%$ for most of the steps except for the lowest radiance levels. 
Table 2.4. Data demonstrating power stability for all six radiance levels over 12 days.

\begin{tabular}{|c|c|c|c|}
\hline $\begin{array}{c}\text { Radiance } \\
\text { Level }\end{array}$ & Mean Power $(\mathrm{mW})$ & $\begin{array}{c}2 \sigma \text { Standard Deviation } \\
(\mathrm{mW})\end{array}$ & $\begin{array}{c}\text { Normalized 2 } \sigma \\
\text { Standard Deviation (\%) }\end{array}$ \\
\hline 1 & 0.269 & .016 & 6.16 \\
\hline 2 & 1.368 & .026 & 1.94 \\
\hline 3 & 2.494 & .036 & 1.46 \\
\hline 4 & 3.70 & .046 & 1.26 \\
\hline 5 & 5.00 & .060 & 1.20 \\
\hline 6 & 6.27 & .064 & 1.03 \\
\hline
\end{tabular}

Figure 2.14 shows the data for the fourth step over the 12-day period for a total of 784 loops. The solid lines indicate thermal cycling periods (i.e. the dewar was allowed to sit at room temperature for two days over the week-end).

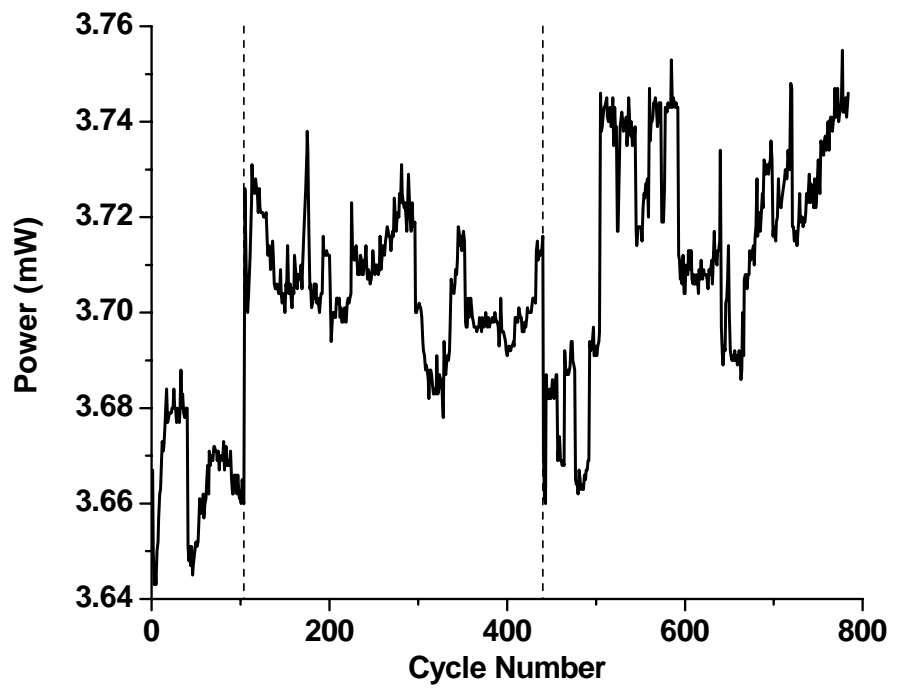

Figure 2.14. Measured power stability over 12 days for the fourth radiance level. The dashed lines show when the dewar was thermally cycled.

PNNL then evacuated the dewar to prevent vacuum degradation. During this evacuation, the dewar shifted position. After PNNL repositioned the dewar, the measured power for the laser increased by approximately $3 \%$ for most of the steps. This increase could be due to better alignment of the power meter or ineffective pump out of the dewar. After this evacuation, PNNL continued the stability testing but did not include this earlier data in the plots and tables that follow in this report. In FY06, PNNL evacuated the dewar again and noticed another increase in power. PNNL believes a proper procedure before collecting data is to gently bake the dewar and to be more careful to prevent fingerprints and body oils from contaminating the surfaces when the dewar is vented to the atmosphere. PNNL did not wear protective gloves when installing the lasers, which helps prevent the possibility of fingerprints and body oils contaminating the surface and outgassing during operation. 
PNNL also began to take more data to accelerate the stability testing. PNNL now is taking up to 256 loops per day. PNNL typically collects 128 loops during the day and then refills the laser dewar with liquid nitrogen and waits an hour before beginning to take another 128 loops in the evening. Table 2.5 shows the results for one day of data collection for all 256 loops in which $1 \%$ stability is still measured except for the lowest level, which is limited by the power meter uncertainty.

Table 2.5. Data demonstrating power stability for all six radiance levels over 256 loops.

\begin{tabular}{|c|c|c|c|}
\hline $\begin{array}{c}\text { Radiance } \\
\text { Level }\end{array}$ & Mean Power $(\mathrm{mW})$ & $\begin{array}{c}2 \sigma \text { Standard Deviation } \\
(\mathrm{mW})\end{array}$ & $\begin{array}{c}\text { Normalized 2 } \sigma \\
\text { Standard Deviation (\%) }\end{array}$ \\
\hline 1 & 0.243 & .003 & 2.5 \\
\hline 2 & 1.388 & .004 & 0.6 \\
\hline 3 & 2.569 & .007 & 0.6 \\
\hline 4 & 3.840 & .013 & 0.7 \\
\hline 5 & 5.170 & .016 & 0.6 \\
\hline 6 & 6.460 & .013 & 0.4 \\
\hline
\end{tabular}

Figure 2.15 shows the data for the fourth step over all 256 loops.

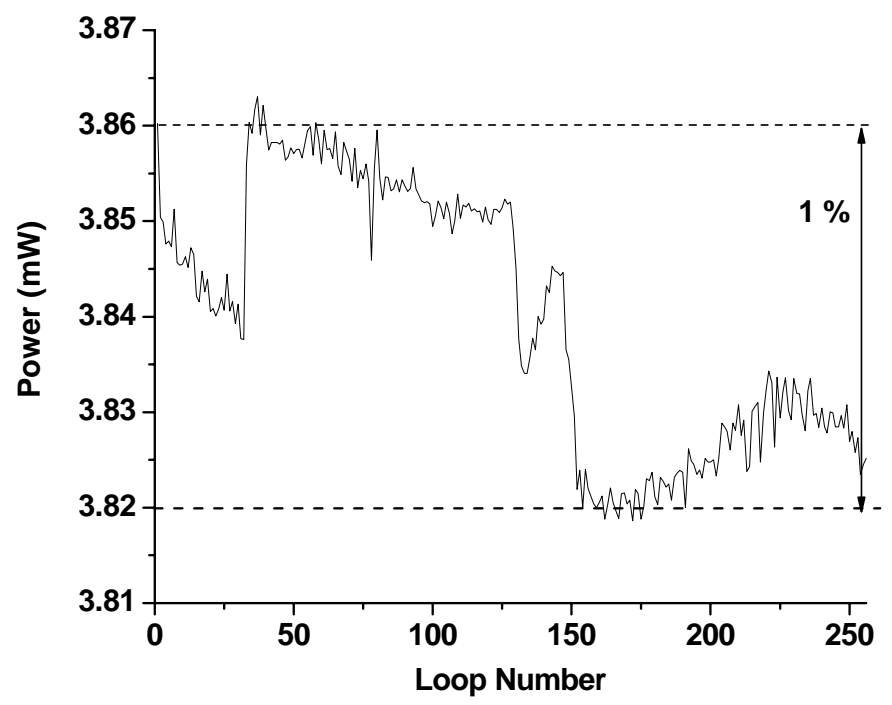

Figure 2.15. Measured power stability for the fourth radiance level over 256 loops. The dashed lines correspond to a $1 \%$ variation.

During this reporting period, almost 18000 loops have been completed. This data, which is taken over 3.5 months, is provided in Table 2.6. The uncertainty for almost all of the steps is around $2 \%$. PNNL did not perform another evacuation of the laser dewar during this time period. 
Table 2.6. Data demonstrating power stability for all six radiance levels over 17,889 cycles.

\begin{tabular}{|c|c|c|c|}
\hline $\begin{array}{c}\text { Radiance } \\
\text { Level }\end{array}$ & Mean Power $(\mathrm{mW})$ & $\begin{array}{c}2 \sigma \text { Standard Deviation } \\
(\mathrm{mW})\end{array}$ & $\begin{array}{c}\text { Normalized 2 } \sigma \\
\text { Standard Deviation (\%) }\end{array}$ \\
\hline 1 & 0.247 & .025 & 10.3 \\
\hline 2 & 1.392 & .026 & 1.9 \\
\hline 3 & 2.573 & .047 & 1.8 \\
\hline 4 & 3.833 & .079 & 2.1 \\
\hline 5 & 5.144 & .102 & 2.0 \\
\hline 6 & 6.433 & .128 & 2.0 \\
\hline
\end{tabular}

Figure 2.16 shows the actual data for the fourth step which illustrates the long-term cyclic variation that is observed. The laser power obtains a maximum after seven days of data collection since the dewar has been thermally cycled (i.e. allowed to warm to room temperature). The peak-to-peak variation is typically on the order of $3 \%$ and is quite reproducible. If the dewar is kept cryogenically cooled for even longer periods than 12 days (which is the typical cool-down period), then the magnitude of the cyclic variation appears to be reduced. This effect is illustrated in both panels c) and g) of Figure 2.16 which resulted from maintaining a dewar temperature of $88 \mathrm{~K}$ for 18 days and 19 days respectively. During this reporting period, however, PNNL has not kept the system cooled longer than 19 days to see if this trend continues. PNNL needs to install an auxiliary reservoir to increase the hold time of the dewar to determine if this cyclic variation diminishes even further.

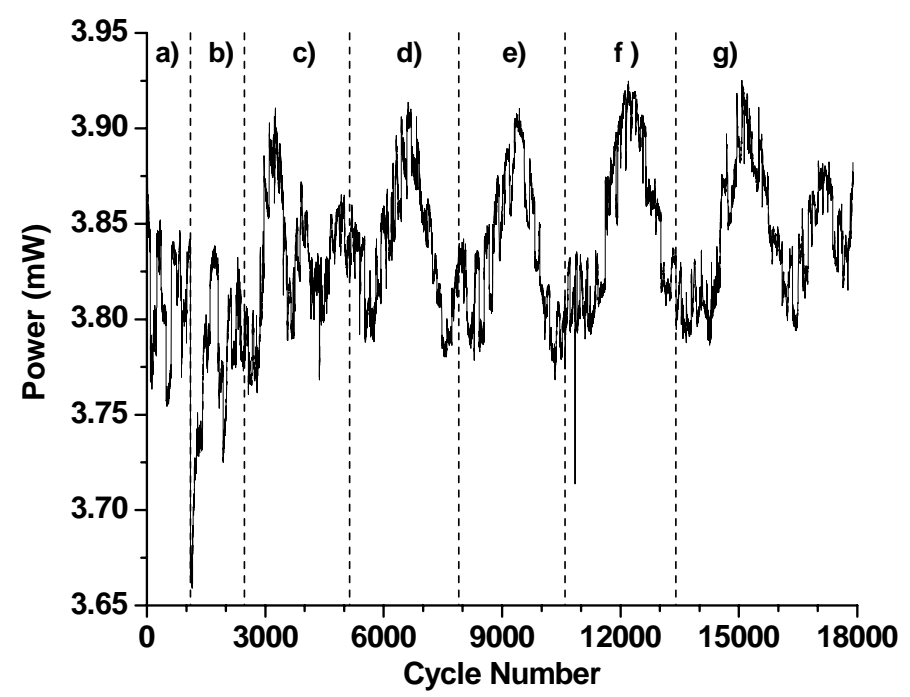

Figure 2.16. Measured output power for the fourth radiance level over 17,889 cycles.

This cyclic variation is not discernable in panels a) and b) of Figure 2.16. Although the power is actually a maximum on the seventh day for the data taken in panel b) of Figure 2.16, the magnitude is less than that observed in panels c) through g). This effect may have resulted from 
the fact that PNNL observed a significant drop in the signal for the first day of the data in panel b) of Figure 2.16 which resulted when the dewar was allowed to warm up over a three day period as illustrated in panel b) of Figure2.16. For the rest of the data, PNNL only allowed the dewar to warm up over a maximum two-day period. This effect may have also resulted from different collection procedures. For this earlier data, PNNL only took data during the day. PNNL did not begin collecting data during both the day and evening hours until Loop number 4140, which occurs in panel c) in Figure 2.16. Once PNNL began collecting data round the clock, the dewar temperature was maintained at $88 \mathrm{~K}$ except when the dewar was thermally cycled over a holiday or week-end.

Figure 2.17 shows the data from the first radiance level which exhibits slightly different behavior than the other five radiance levels. The power appears to have dropped by $0.04 \mathrm{~mW}$ after the first three cycling periods and then a minor decline after the fifth thermal cycle to reach a final value around $0.24 \mathrm{~mW}$. This step is more sensitive to any subtle effects such as reproducibility of the temperature sensor with thermal cycling.

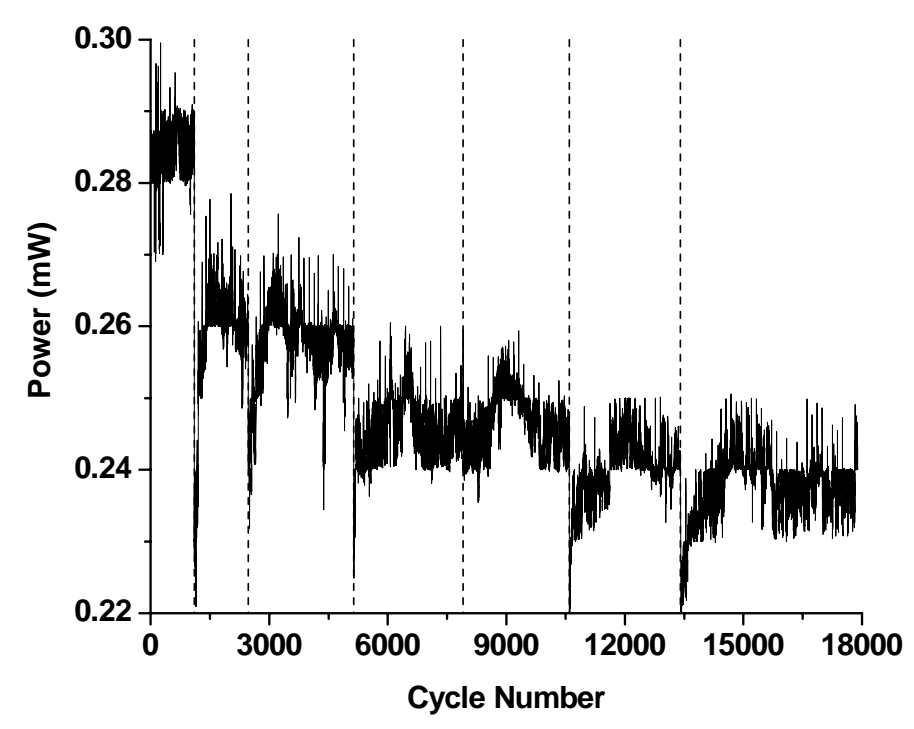

Figure 2.17. Measured output power for the first radiance level over 17,889 cycles.

All of these measurements are performed in an uncontrolled laboratory, and the dewar pressure is unregulated. For optimal performance, the measurements should be performed in a temperature controlled enclosure, and a pressure relief valve should be used on the dewar to maintain a constant dewar head pressure. In fact, PNNL noticed the power depended on the cap position of the dewar after 3600 loops. Figure 2.18 shows how the power changes from the position of the dewar cap. In a) the cap is partially seated and then the cap is completely seated in b). The cap is completely removed in c) and then replaced on d). The power is highest when the cap is completely seated on the dewar. The total change in power is only $0.03 \mathrm{~mW}$, which is less than a $1 \%$ change at this output power. A similar percent change is observed for all six steps. From this point, PNNL makes a more concerted effort to ensure the cap is completely on before beginning all experiments. 


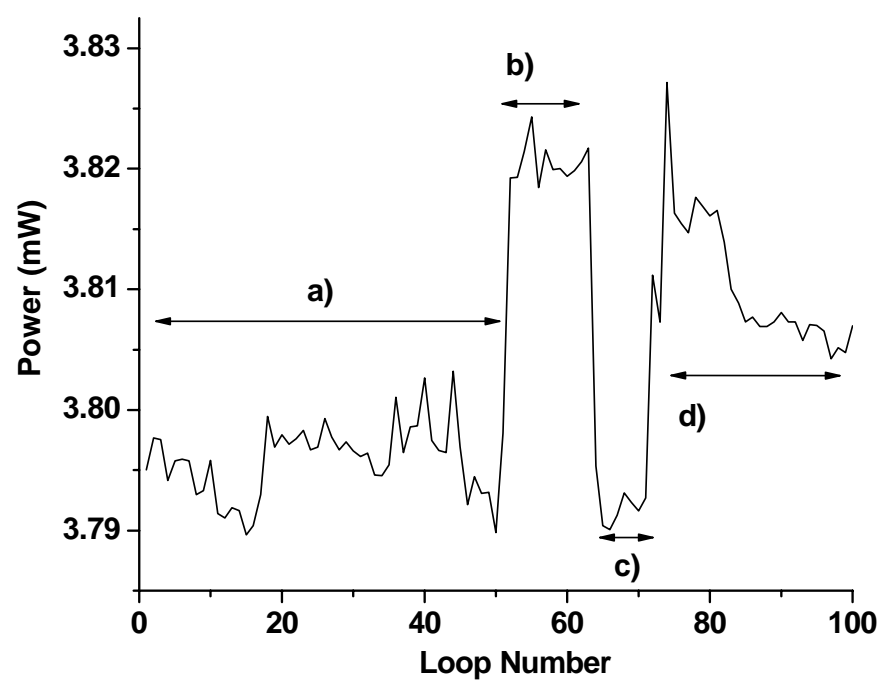

Figure 2.18. Effect of dewar cap position on output power. In a) the cap is partially seated whereas in b) and d) the cap is completely seated on the dewar. In c) the cap is completely off. 



\subsection{Final Remarks}

PNNL has demonstrated a multiple radiance level scheme using a QC laser that provides $1 \%$ stability over the short-term. Further improvements in the measurement set-up are necessary to demonstrate this $1 \%$ stability over the long-term. In FY06, PNNL plans to install an auxiliary liquid nitrogen reservoir on the dewar to avoid thermal cycling to determine its effect on the observed cyclic variation. A second laser system will also be set up to begin testing other modifications. For instance, PNNL plans to incorporate a new laser that is mounted on a larger chip assembly to allow on-chip mounting of the temperature sensor. PNNL also plans to incorporate a temperature sensor that demonstrates higher repeatability with thermal cycling (such as a platinum resistance thermometer). With this new laser system, PNNL will determine if this set-up provides better performance.

In FY06, PNNL will also verify that the timescale for the multi-radiance level scheme can be reduced to further minimize the impact of the calibration procedures. Goals are to decrease the time scale so that the entire procedure is less than two minutes. The current sequence lasts for 184 seconds, which includes 40 seconds below threshold at the start of the sequence and 24 seconds below threshold at the end of the sequence. The 24 seconds at the end of the sequence is easily eliminated, and PNNL believes that 10 seconds can be eliminated at each step (including the step below threshold) so that another 70 seconds could be shaved from the time. Thus, the entire sequence would last for 90 seconds.

PNNL will continue the long-term testing on the current system to determine the lifespan of the QC laser under these conditions. This step is to verify QC lasers are viable for satellite platforms that involve a 3-5 year span. PNNL does not believe this lifetime is unreasonable and has been using some of its QC lasers in the laboratory for five years with no qualitative degradation.

PNNL will also maintain the partnership with Princeton University to continue the development of lasers that span the $7.5-13.5 \mu \mathrm{m}$ region with a minimal number of laser sources. Finally, PNNL plans to build miniature custom current controllers and temperature controllers to minimize the size of the electronic components for the system. These steps should provide a calibration system that is a viable alternative to on-board blackbodies with reduced size, weight, and power requirements. 



\section{Distribution}

No. of

Copies

\section{OFFSITE}

LTC Ariel Cuadrado

United States DOE

NNSA/NA-22

1000 Independence Ave. SW

Washington, DC 20585

Dr. Rhys M. Williams

United States DOE

NNSA/NA-22

1000 Independence Ave. SW

Washington, DC 20585

Dr. David Berry

United States DOE

NNSA/NA-22

1000 Independence Ave. SW

Washington, DC 20585

Mr. Ralph Hastings

United States DOE

NNSA/NA-22

1000 Independence Ave. SW

Washington, DC 20585

Mr. Eric Sander

United States DOE

NNSA/NA-22

1000 Independence Ave. SW

Washington, DC 20585

Mr. W. Randy Bell

United States DOE

NNSA/NA-22

1000 Independence Ave. SW

Washington, DC 20585
No. of

Copies

\section{ONSITE}

\section{Pacific Northwest National Laboratory}

Broocks, BT

K5-25

Bruckner-Lea, C

K5-25

Clemmer, RG

$\mathrm{K} 8-02$

Dudder, GB

$\mathrm{K} 8-02$

Myers, TL

$\mathrm{K} 5-25$

Phillips, MC

$\mathrm{K} 5-25$

Schultz, JF (10)

$\mathrm{K} 5-25$

Sharpe, SW

K8-88

Information Release Office (7)

Distr.1 
